\title{
More than Money: Social Class, Income, and the Intergenerational Persistence of Advantage
}

\author{
Carina Mood
}

Stockholm University

\begin{abstract}
I provide a uniquely comprehensive empirical integration of the sociological and economic approaches to the intergenerational transmission of advantage. I analyze the independent and interactive associations that parental income and social class share with children's later earnings, using large-scale Swedish register data with matched parent-child records that allow exact and reliable measurement of occupations and incomes. I show that parental class matters at a given income and income matters within a given social class, and the net associations are substantial. Because measurement error is minimal, this result strongly suggests that income and class capture partly different underlying advantages and transmission mechanisms. If including only one of these measures, rather than both, we underestimate intergenerational persistence by around a quarter. The nonlinearity of the income-earnings association is found to be largely a compositional effect capturing the main effect of class.
\end{abstract}

Keywords: social mobility; income mobility; economic mobility; intergenerational transmission; social class

Citation: Mood, Carina. 2017. "More than Money: Social Class, Income, and the Intergenerational Persistence of Advantage." Sociological Science 4: 263-287.

Received: January 3, 2017

Accepted: February 21, 2017

Published: April 5, 2017

Editor(s): Jesper Sørensen, Kim Weeden

DOI: $10.15195 / \mathrm{v} 4 . \mathrm{a} 12$

Copyright: (C) 2017 The Author(s). This open-access article has been published under a Creative Commons Attribution License, which allows unrestricted use, distribution and reproduction, in any form, as long as the original author and source have been credited. @()
$\mathrm{C}^{\mathrm{VEN}}$ in modern Western nations, children are born with different opportunities in life because of the resources in their family of origin. Despite extensive research on the intergenerational transmission of advantage, we still know little about what it is about parents that matters and why. The literature generally uses one omnibus variable (commonly occupation-based in sociology and income-based in economics) as a catch-all for an unknown and normally undefined bundle of social and economic advantages, something which not only leaves us with a vague picture but also underestimates the transmission of advantage.

This article aims to bring some light into the black box of intergenerational transmission by integrating the sociological and economic approaches and studying the independent and interactive associations that parental income and social class share with children's later earnings. Reliable separation of the independent contributions of the parental variables requires large and detailed data, and I therefore use full-population Swedish register data that allow (1) exact and reliable measurement of occupations and incomes of both parents and (2) control for an extensive range of other potentially important parental variables. My main questions are: For parental income and social class, how strong are the unconditional and conditional associations with children's earnings? To what extent is the contribution of one captured by the other? Does the association between parental income and child earnings vary by parental social class? And how much do we underestimate intergenerational persistence if not accounting for both factors? 


\section{Parental Social Class and Income as Measures of Parental Advantage}

The standard approach in sociological and economic mobility research is to treat the variable in focus (generally class or income) as an omnibus measure capturing a bundle of different valued aspects of life (see reviews in Breen and Jonsson 2005 and Blanden 2013). Similar practices are common also in other disciplines such as epidemiology, where a wide range of operational definitions have been used as omnibus measures of socioeconomic status (SES). In line with this omnibus perspective, the term "social mobility" has lately been used as a generic term in studies of intergenerational associations in advantage, however measured (Clark 2014; Clark et al. 2015; Blanden and Machin 2007). In the "omnibus" view, income and class mobility speak to the same question-in the words of Blanden, Gregg, and Macmillan (2013:542), "both approaches are trying to assess long-term or permanent socio-economic status but measure it in different ways." This (implicit or explicit) reference to some general unspecified advantage is, however, misleading if income and social class represent partly different bundles of advantages and disadvantages and different underlying transmission mechanisms. The empirical findings of a limited overlap of economic and social mobility suggest that this may very well be the case (Breen, Mood, and Jonsson 2016; Blanden 2013).

A sociologist would not dispute that there is more to social class than economic conditions (e.g, job security, power, autonomy, work conditions), but it is not as evident that these noneconomic features of social classes carry over to advantages and disadvantages for children in adult age. Various noneconomic mechanisms have been proposed, such as transmissions of knowledge, preferences, and interests (Jonsson et al. 2009). Nevertheless, recent discussions about how to interpret discordant results on income mobility and social mobility (Erikson and Goldthorpe 2010; Blanden et al. 2013; Blanden 2013) are almost exclusively in terms of the economic aspects of social class. The debate concerns how well the normally used income and social class variables capture long-term economic conditions, with the implicit premise that economic conditions are what drive both social and income mobility. In survey data, occupational variables may perform better as proxies for long-term income than shorter-term income variables (Hauser and Warren 1998), and Erikson and Goldthorpe (2010:211) therefore argue that "it would appear that the class mobility regime more fully captures the continuity in economic advantage and disadvantage that persists across generations."

With this increasing focus on parental economy, the distinction between economic and social mobility risks becoming a measurement issue rather than a theoretical one. If social class is largely reduced to a proxy for economic conditions, it risks becoming obsolete if better economic variables become available (e.g., from tax registers). Another issue is that if parental income and social class are independently related to some child outcome, and if they are not perfectly overlapping, using only one of these variables will give a smaller estimated persistence than if both are used. Similarly, if both mothers and fathers matter to children, including the income or class of only one of them in the model will lead to an underestimation. 
In the field of intergenerational studies, comparisons across countries and over time abound. The differences that we observe using one parental variable (say, income) will reflect also the association of the outcome with the other parental variable (say, social class) only to the extent that the two parental variables are correlated. So, the estimated coefficient for parental income will reflect (a) the association between parent income and the child outcome, (b) the association between parent income and parent social class, and (c) the association between parent social class and the child outcome, and differences across countries or over time can reflect any of these.

Researchers are of course aware of the potential impact of omitted variables, at least in principle. In Solon's (2004) theoretical model of intergenerational income associations, the part of the association that is not produced by parental income is framed in terms of the heritability of "endowments," which can in principle be taken to include anything affecting children's incomes. In practice, however, economists tend to equate endowments with cognitive and noncognitive skills, and they generally ignore them in cross-country or over-time comparisons, because in their interpretation, "the heritability of endowments is unlikely to differ significantly across developed countries or over time" (Black and Devereux 2011: 1,500). This approach renders invisible parental variables such as social class. If the association between parental class and children's outcomes (or between parental class and income) varies across different countries and periods, this will affect differences in intergenerational income associations.

\section{The Contribution: A Multidimensional and Transparent Parental Model}

This article builds on previous findings suggesting a limited empirical overlap of social mobility (i.e., the class-class association) and income mobility (i.e., the income-income or earnings-earnings association) (Breen et al. 2016; Blanden 2013), and I here integrate the study of parental class and income into one analysis with one common outcome (child earnings) in order to better understand the substantive contribution of each in predicting children's later success. An analysis of this kind is only meaningful with large and detailed data with minimal measurement error because the possibilities of distinguishing the role of one parental variable from another depends on how much measurement error they contain (for example, the worse the measure of parental income, the higher is the risk that unmeasured variation in income is picked up by the parental class variable). My data are extraordinary in this respect: throughout, I exploit matched parent-child data for 15 entire Swedish cohorts born between 1958 and 1972 in which the role of parental social class and incomes for child outcomes can be reliably assessed with full consideration of the role of both parents. Measures of disposable income are constructed using register data covering all official (work and benefit) income sources and taxes for both parents over nine years and matched occupations for both parents using data from six censuses. This makes the data uniquely reliable 
and free from attrition, selective missingness, and recall errors-problems that loom large in survey data.

I choose to measure disposable income in the parental generation but earnings in the child generation because I want to capture the economic situation during childhood as fully as possible while avoiding estimates that reflect mechanisms of partner choice and family processes in the child generation. The focus on child earnings rather than education or social class is based on earnings being a more "final" measure of success, affected by rather than affecting education and occupation. ${ }^{1}$

Separating the contribution of different parental factors to child outcomes in a reliable way using normal survey data sets requires strong parametric assumptions. As shown by Heckman, Ichimura, and Todd (1998), the standard regression approach can give large biases in the estimated effects of interest when ranges and distributions of the control variables vary across the values of the variable in focus. With my large and detailed data, I can avoid this problem by estimating effects of one variable across its range of variation while explicitly holding other relevant variables constant at given levels. With such results as a backdrop, I turn to regressions to be able to include more variables in a digestible way.

Previous research have shown associations between parental wealth and children's education net of parental income (Pfeffer and Hällsten 2012), so even though my measure of parental income is uniquely comprehensive, there is a risk that it does not fully capture parents' economic conditions. In order to reduce this risk, I therefore also include parental wealth in the analysis. ${ }^{2}$

With my analyses, we can say whether parental class is related to children's outcomes net of parents' economic conditions (as measured by income and wealth). What we still cannot say is what this association consists of: it may partly be a causal effect, going through some other mechanism than income, but it may also partly reflect effects of education or other factors preceding social class. In order to make the picture as clear as possible, I will take several other parental variables into account. Throughout, however, the focus is on disentangling the independent contribution of social class from that of income, as these are the two major variables in the mobility literature.

My analyses cover Sweden only. Keeping in mind that cross-country comparisons are difficult to make, economic and social mobility across generations appears to be higher in Scandinavia than in most other studied countries (e.g., Breen and Jonsson 2005; Blanden 2013; Gregg et al. 2013). This is in line with what we can expect if egalitarian policies make children's living conditions and opportunities less restricted by their parents' situation. More specifically, we can expect egalitarian policies to suppress the impact of parental economic resources more than the impact of noneconomic resources, and such a process may lie behind the fact that cross-country differences are more clearly evident for income mobility than for social mobility (Blanden 2013). If this is the case, we can expect that the effect of income net of parental social class varies more across countries than the effect of social class net of income, the latter to a higher extent representing mechanisms such as preference and skill transmission, which are less amenable to policy influences. However, welfare state effects on economic mobility would most likely be more 
prominent if children's economic outcomes were measured net of all taxes and benefits than if measured here as gross earnings.

\section{Data and Variables}

All data come from national registers and censuses covering the entire Swedish population aged up to 75 in the respective year. I retain only Swedish-born individuals born between 1958 and 1972 and link their data to parental records using a multigenerational identifier. One set of parents, biological or adoptive, is identified for each child, with adoptive parents given priority if both kinds exist.

Although it is common in studies of income mobility to use fathers' earnings as the independent variable, this is a deficient proxy for family economic resources because mothers can obviously also have incomes, and incomes need not come from work alone. I therefore use a more comprehensive measure of parental income by averaging the family disposable income for both parents at child ages 10-18. It is constructed in the following steps:

1. Calculate the disposable family income of (a) the biological/adoptive mother and (b) the biological/adoptive father for each year when the child is 10-18 years. Include all parental and partner incomes (from work and benefits), but not incomes of any children living in the household, and subtract taxes. Zero and negative incomes are missing-coded (affecting only around 0.2 percent of parents in a given year-zero incomes are very rare because families with children $<19$ years should receive universal child benefits), and incomes above four standard deviations are top-coded (affecting around 0.3 percent of parents a given year). Families in which a parent or a parent's partner has self-employment as the major income source ( $>50$ percent) are also missingcoded (affecting 5-6 percent of parents a given year) because of unreliability in self-employment income as a measure of economic living standards.

2. Take the average of the mother's and the father's disposable family incomes, for each year when the child is 10-18 years. If the parents live together, this variable gives the disposable income of that family, otherwise we get the average for two families. If the variable for one parent is missing, the nonmissing one is used.

3. Take the average of the yearly parental average disposable income over all years when the child is 10-18 years old. Missing-code if more than four years are missing.

4. Standardize this variable per child cohort. Observe that I do not take logarithms of the income measures but leave the functional form of the relationship an empirical question.

Child earnings consist of the average yearly income at ages 35-40 from employment and self-employment, and if nothing else is stated, also include earningsrelated benefits (e.g., sickness or parenting benefits). Children whose primary income source ( $>50$ percent) in a given year is self-employment are missing-coded 
(around 3 percent in a given year), and earnings above four standard deviations in a given year (around 0.3 percent) are top-coded. Zero earnings are missing-coded if disposable family income is 0 (affecting a handful of persons a given year). The averaged variable is missing-coded if earnings are missing during more than two years in the 35-40 age span, and the final variable is z-standardized within each cohort and for men and women separately.

Parental social class is coded from records about occupation in the censuses 1960, $1970,1975,1980,1985$, and 1990. Priority is given to the occupations that the parents held when the child was aged 10-15. All censuses are, however, used in order to get as many nonmissing records as possible. Overtime class mobility among adults is low (Jonsson 2001), so this procedure is unlikely to be problematic. Parents who are classified as self-employed or farmers are excluded. Occupations are coded into EGP classes (Erikson and Goldthorpe 1992): I = upper middle class (professionals, higher administrative, executives), II = middle class (semiprofessionals [e.g., nurses], midlevel administrative, low-level managers), III = routine nonmanual (clerks, secretaries, office workers), VI = skilled manual workers, VII = unskilled manual workers. The social class of father and mother are combined into 21 categories. For ease of presentation, the 21 categories are in some analyses (predominantly in graphs) collapsed to five larger groups, building on an empirical pattern of a major divide between the manual and nonmanual classes and distinguishing the following categories: (1) both parents have nonmanual jobs, and at least one has a high- or midservice class one; (2) both parents have routine, nonmanual jobs; (3) both parents have manual-class jobs; (4) one parent has a high- or midservice job, the other has a manual job; and (5) one parent has a routine nonmanual class job, the other a manual job. Table 1 shows the class categorizations. ${ }^{3}$ In some analyses, I also operationalize class in terms of 77 microclasses that are single occupations or groups of closely related occupations.

Parental wealth is measured for each parent as the average net worth of the five years between 1968 and 1989 with the highest recorded taxable wealth (in tax records). The average of the mother's and father's wealth is then top-coded at four standard deviations within each cohort and standardized per cohort. I have also tested wealth defined as the average over the whole period or for two subperiods with very different taxation limits (1968-1977; 1978-1989), but the chosen definition had the strongest association to child earnings.

Parental education is the level and field of the highest recorded education found in the educational register from 1990 to 2007 or in any of the censuses. There are seven levels (ranging from comprehensive school to $\mathrm{PhD}$ ) and nine fields (general, teaching, humanities, social science, natural science, technical, agriculture, health, and service), but not all combinations of levels and fields exist. Small categories $(N<50)$ are excluded. In total, 47 different educational indicators are used as dummy variables.

Municipality of residence during childhood is measured at age 15 and is included as 285 dummy variables. 218 observations were coded as missing because the municipality could not be identified.

Family type is assessed in the census and recorded in three categories: (1) parents live together at child age 15, (2) parents separated between child ages 10 and 15, 
Table 1: Parental class categories (combining mothers' and fathers' social class). All children born between 1958 and 1972 with nonmissing information on parental income and own earnings $(N=1,140,049)$.

\begin{tabular}{|c|c|c|}
\hline & Observations & Percent \\
\hline \multicolumn{3}{|l|}{ Category 1: Upper middle and middle class } \\
\hline Both parents upper middle & 28,836 & 2.5 \\
\hline Mix upper middle + middle & 62,155 & 5.5 \\
\hline Mix upper middle + routine nonmanual & 43,646 & 3.8 \\
\hline Mix upper middle + not working & 5,827 & 0.5 \\
\hline Both parents middle & 52,045 & 4.6 \\
\hline Mix middle + routine nonmanual & 84,799 & 7.4 \\
\hline \multirow[t]{2}{*}{ Mix middle + not working } & 9,357 & 0.8 \\
\hline & 286,665 & 25.1 \\
\hline \multicolumn{3}{|l|}{ Category 2: Routine nonmanual class } \\
\hline Both parents routine nonmanual & 41,729 & 3.7 \\
\hline \multirow{2}{*}{ Mix routine nonmanual + not working } & 10,312 & 0.9 \\
\hline & 52,041 & 4.6 \\
\hline \multicolumn{3}{|l|}{ Category 3: Mix upper/middle class + manual } \\
\hline Mix upper middle + skilled manual & 8,640 & 0.8 \\
\hline Mix upper middle + unskilled manual & 28,374 & 2.5 \\
\hline Mix middle + skilled manual & 34,968 & 3.1 \\
\hline \multirow[t]{2}{*}{ Mix middle + unskilled manual } & 92,910 & 8.1 \\
\hline & 164,892 & 14.5 \\
\hline \multicolumn{3}{|l|}{ Category 4: Mix routine nonmanual class + manual } \\
\hline Mix routine nonmanual class + skilled manual & 58,703 & 5.1 \\
\hline \multirow[t]{2}{*}{ Mix routine nonmanual class + unskilled manual } & 115,710 & 10.1 \\
\hline & 174,413 & 15.3 \\
\hline \multicolumn{3}{|l|}{ Category 5: Manual } \\
\hline Both skilled manual & 19,311 & 1.7 \\
\hline Mix skilled and unskilled manual & 208,886 & 18.3 \\
\hline Mix skilled manual + not working & 17,992 & 1.6 \\
\hline Both unskilled manual & 188,113 & 16.5 \\
\hline \multirow[t]{2}{*}{ Mix unskilled manual + not working } & 26,582 & 2.3 \\
\hline & 460,884 & 40.4 \\
\hline No parent working in any census & 1,154 & 0.1 \\
\hline Total $N$ & $1,140,049$ & 100.0 \\
\hline
\end{tabular}

and (3) parents separated before age 10 (or never lived together, which is, however, unusual in Sweden).

Parent immigrant status is coded as 1 if both parents are born outside Sweden, 0 otherwise. More detailed definitions have no meaningful impact on the results of interest. 
Sibship size and sibling order is a combined variable with 22 categories, showing how many siblings the child has (categories from 0 up to 5 or more) and what place the child has in the sibling order (categories from first to sixth or higher).

Table A1 in the online supplement gives the descriptive statistics for the included variables (excluding those with very large numbers of categories).

\section{The Descriptive Picture: Bivariate Associations between Parental Income/Parental Class and Child Earnings}

Figure 1 shows the bivariate association between parental income and child earnings, with each point representing a percentile in the parent income distribution and child and parent income being the mean within each of these percentiles. Incomes are standardized for sons and daughters separately, meaning that the curves for men and women are not comparable in terms of levels. Two different income measures are shown: pure earnings (dots) and earnings+ $(\mathrm{x})$, which denotes earnings plus earnings-related benefits (of which the most common are parental and sickness benefits). For men, including earnings-related benefits makes no difference, so the two income series overlap almost exactly, whereas for women we see that intergenerational persistence is slightly stronger when including earnings-related benefits. This is because the measurement of earnings occurs at an age (35-40) when childbearing is common and many women take out parental leave. The level of parenting benefits is determined by previous incomes, so if we exclude parenting benefits, we underestimate the income variation among women. In the following, I therefore focus on the earnings+ measure.

As expected, there is a strong relation between parent income and child earnings, and it is stronger for men than for women and somewhat nonlinear, especially for men. ${ }^{4}$ The nonlinear shape of the association does not correspond to the conventionally assumed log-log form, and this holds also when excluding zero earnings. Figure A1 and Table A2 in the online supplement give results using logged incomes. In this case, zero incomes are excluded, as results are sensitive to imputation of arbitrary values. The most visible effect of logging is the stretching out of the scale at low parental incomes, resulting in seemingly low marginal increases in children's predicted earnings for parental income increases at the lowest end.

Figure 1 suggests that for parental incomes below the mean, a standard deviation's increase predicts an increase of child earnings of 20-30 percent of a standard deviation, whereas the corresponding increase for parental incomes above the mean is 30-40 percent. For very high incomes, the estimated marginal effects decrease again. The strength of the association is around what we would expect from previous results on income mobility in Sweden using similar income definitions (Jonsson, Mood, and Bihagen 2010; Mood, Jonsson, and Bihagen 2012; Gregg et al. 2013; Breen et al. 2016). The nonlinearity shows that income differences among parents at the lower end of the income distribution are less reflected in the earnings of their children than income differences among higher-income parents, suggesting that there are no particular "poverty effects" in the sense that growing up with very low incomes means a disproportionate disadvantage. 


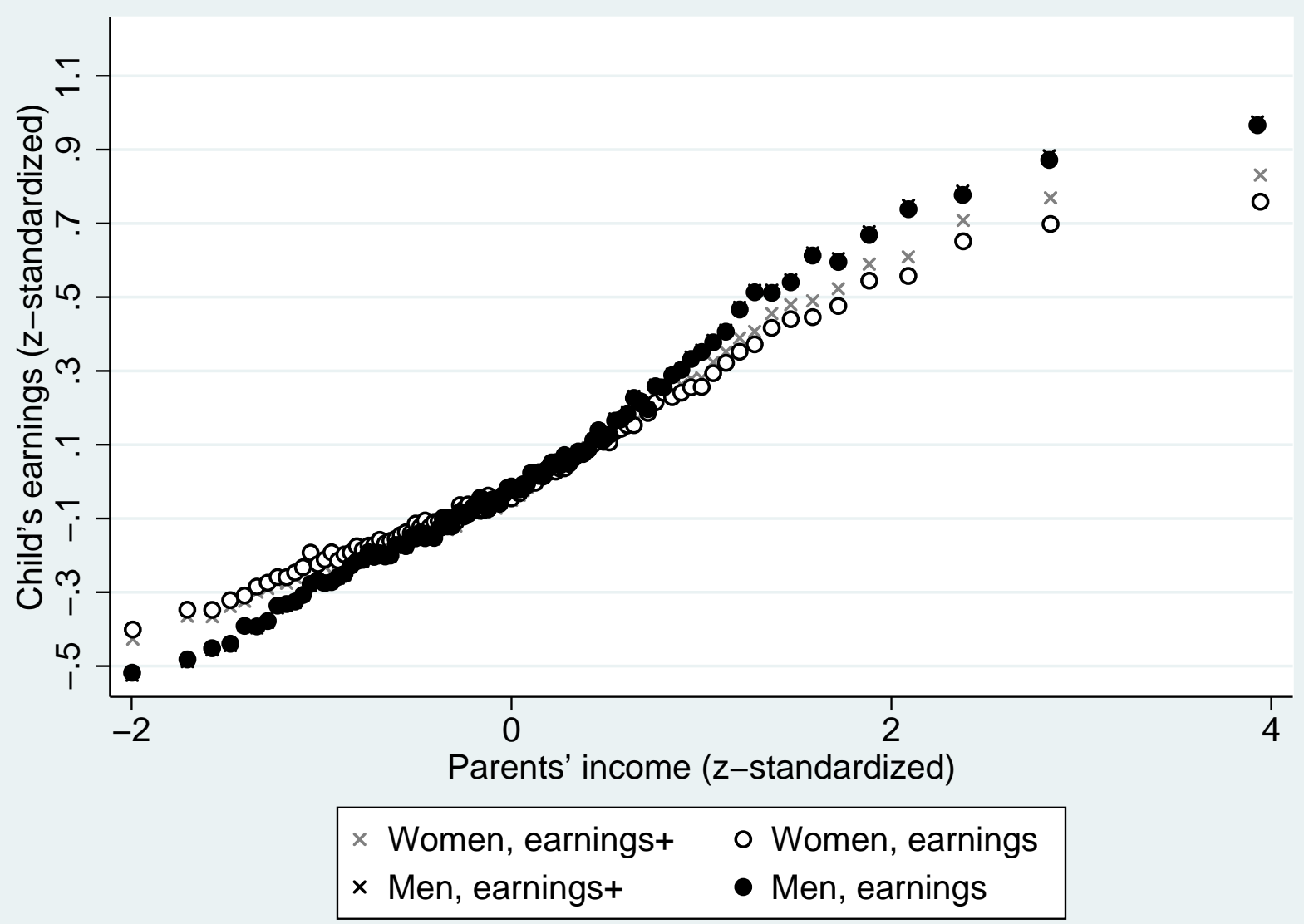

Figure 1: Child earnings by parental income.

Looking at the association between parental class and child earnings is not as straightforward, as we need to consider the combination of parental classes. Assigning the highest class as the family class—assuming that it is "dominant"-is a common practice, but this would be misleading. Figures 2 and 3 give the earnings for sons and daughters of parents with different social class combinations, and it is obvious that the class mix matters. It is particularly striking that children who have one parent with a nonmanual occupation have on average lower adult earnings if the other parent has a manual occupation than if the other parent does not work at all. The differences in child earnings by parental class are large: the average earnings differ by around one standard deviation between those with both parents in a upper middle class job and those whose parents are both unskilled manual workers. Overall, patterns are similar for sons and daughters. 


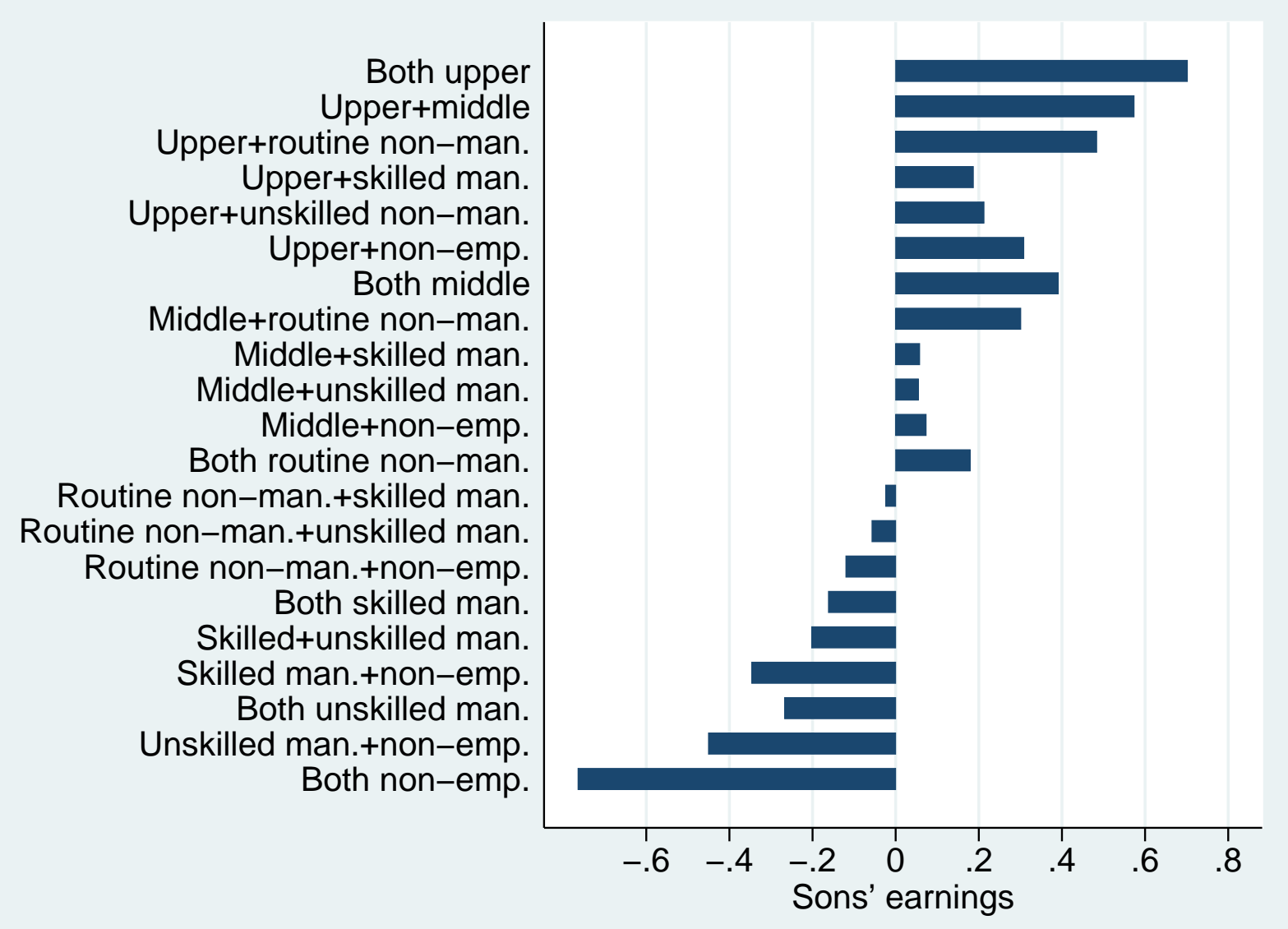

Figure 2: Sons' earnings by parental class.

\section{Disentangling the Independent Contributions of Parental Class and Parental Income}

Figure 4 (sons) and Figure 5 (daughters) distinguish five combinations of father's and mother's social class (see Table 1).The association between parents' and child's income is now shown within each of these class groups, and the bivariate association in Figure 1 is kept as a reference (the black curve). Percentiles are still taken across the entire income distribution (not within classes), meaning that the points in the graph no longer represent equal numbers of parent-child pairs. If less than 150 observations within a parental class belong to a given parental income percentile, it is suppressed in the graph. Figures 4 and 5 reveal that the nonlinearity in the income-earnings association seen in Figure 1 was almost entirely a compositional effect: the income-earnings association is stronger at higher incomes because more high-income parents are in service class occupations. Within each class, the incomeearnings association is closer to linear but with somewhat decreasing effects at the highest parental incomes within each class. There is also a tendency of children in upper middle class families with the very lowest incomes to have unexpectedly high 


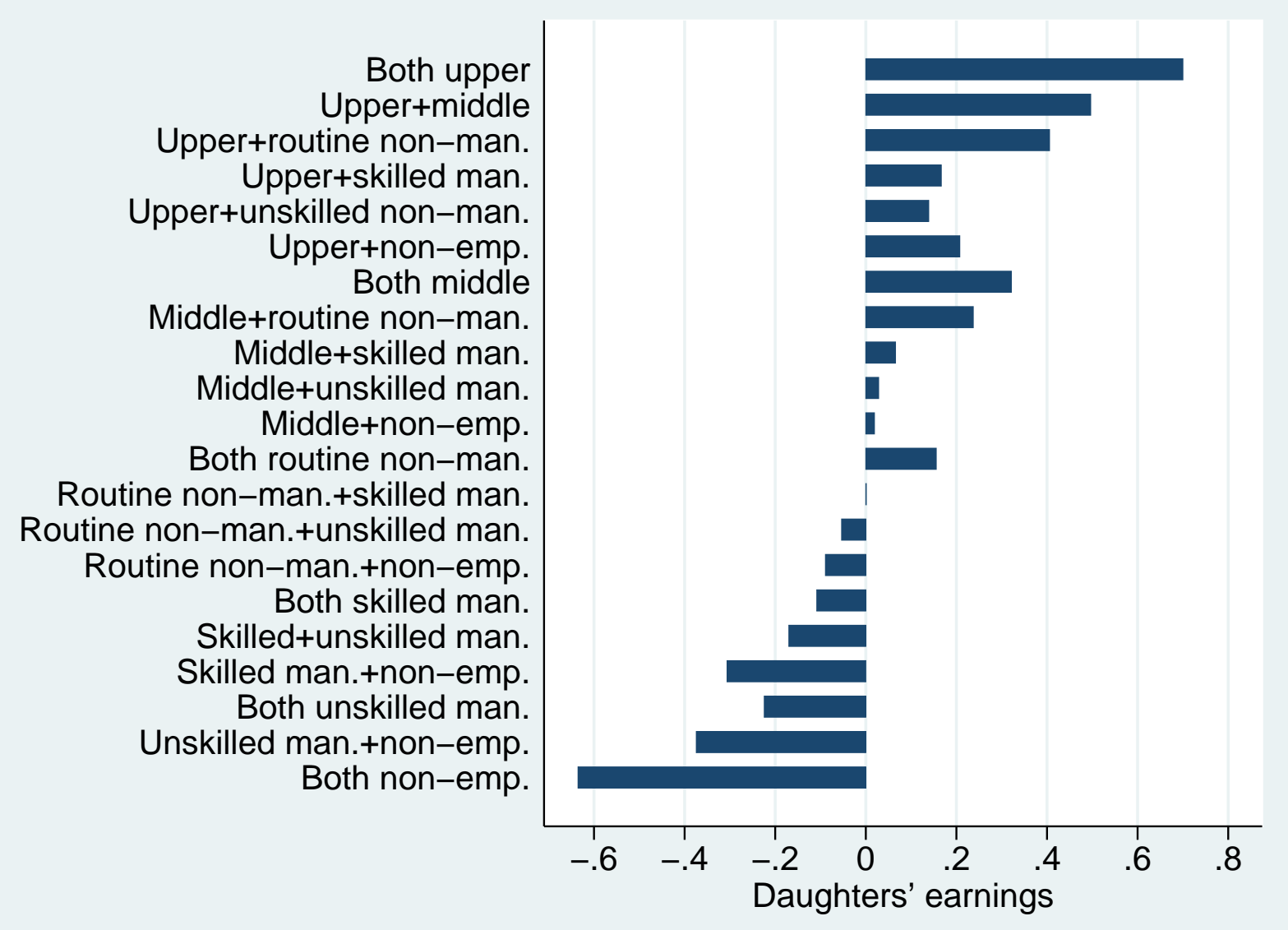

Figure 3: Daughters' earnings by parental class.

earnings, which raises the suspicion that their parents had higher living standards than their registered incomes imply. This warrants some caution in interpreting a flatter association at the lowest end of the distribution in Scandinavian countries in substantive terms (e.g., Bratsberg et al. 2007).

Figures 4 and 5 furthermore suggest that there is both a class effect term that is independent of income (seen from the distance between different classes at a given income level) and an income effect term that is independent of class (seen from the fact that each class cluster has an upward slope). Across most of the parental income range, the distance between children from the high-service class and from the manual class is 0.3 to 0.4 standard deviations, and within classes a one standard deviation's distance in parental income predicts around 0.2 standard deviations' higher child earnings. Both these associations are somewhat smaller for women than for men. The earnings gap between children from the highest and the lowest class is rather similar across the parental income distribution, only increasing somewhat at the highest and lowest parental income levels. As in Figures 2 and 3, we see that a coding of "dominant" class would be misleading: The class of both 


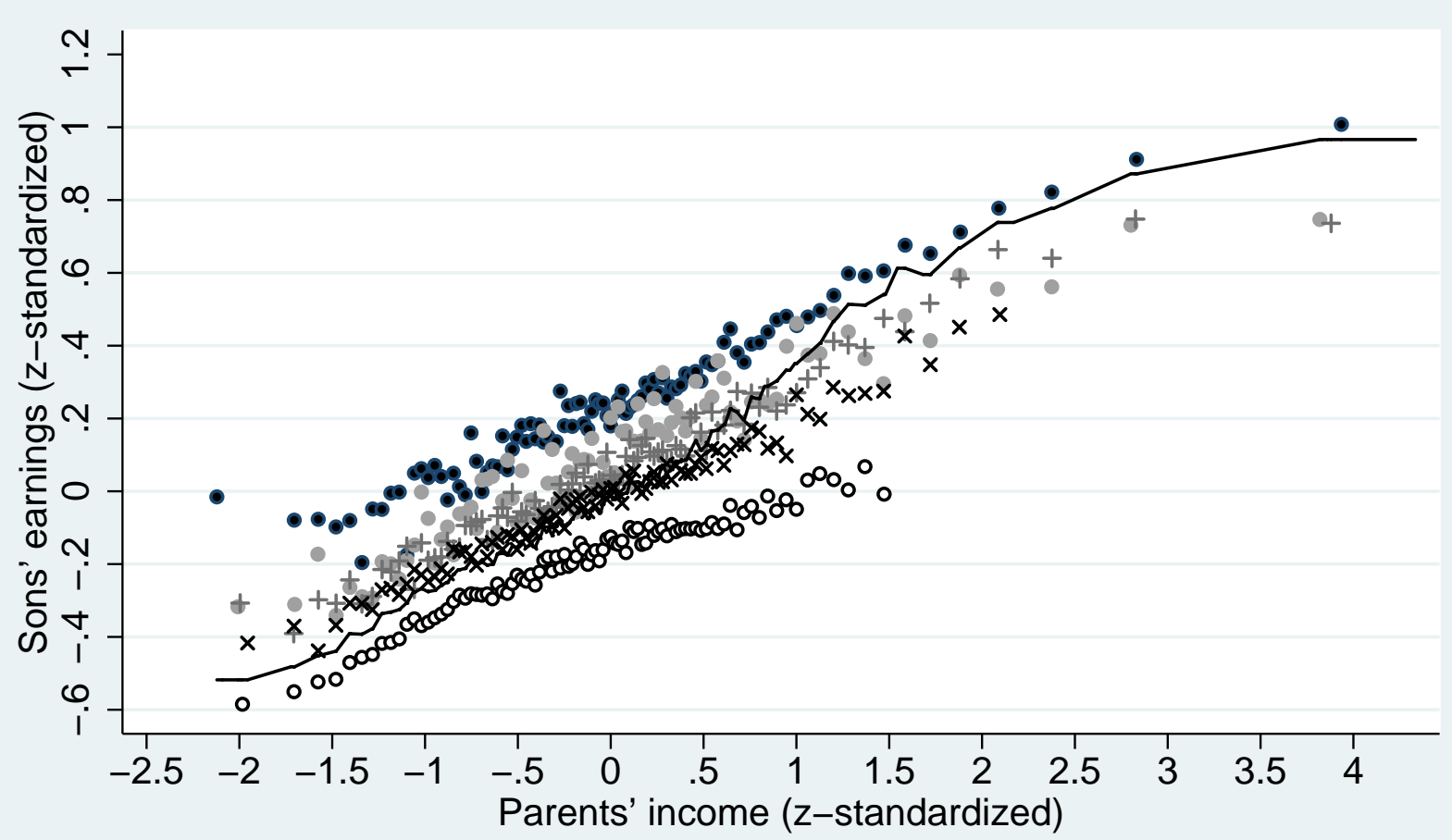

\begin{tabular}{|lll|}
\hline $\begin{array}{lll}\text { - Both upper or middle } \\
+ \text { Mix upper/mid+manual }\end{array}$ & $\times$ & Both routine non-man. \\
- Both manual & $\times$ & Mix routine non-man.+man. \\
\cline { 2 - 2 }
\end{tabular}

Figure 4: Sons' earnings by parental income and parental social class.

parents matter roughly equally, with children of "mixed" class background lying in between those with both parents of the same class (higher or lower).

A more extensive number of social classes give results in line with the ones seen in Figures 4 and 5, as does the comparison of separate microclasses of sufficient size (not shown). The most consistent pattern that emerges throughout is one of a nonmanual-manual divide: children of parents in manual occupations have lower earnings even when parents have similar incomes, and we see a substantial disadvantage even for those with only one parent in a manual occupation.

Clearly, then, there is more to class than income: parents' social class or occupation is also associated with the future earnings of children at a given level of parental income during childhood. Although the observed contribution of class need not reflect a causal effect, it shows that the common justification of using parental class as a presumably good proxy for economic conditions is at least partly misguided: parental class captures also other transmission mechanisms that are substantively important and no less interesting than the economic ones. 


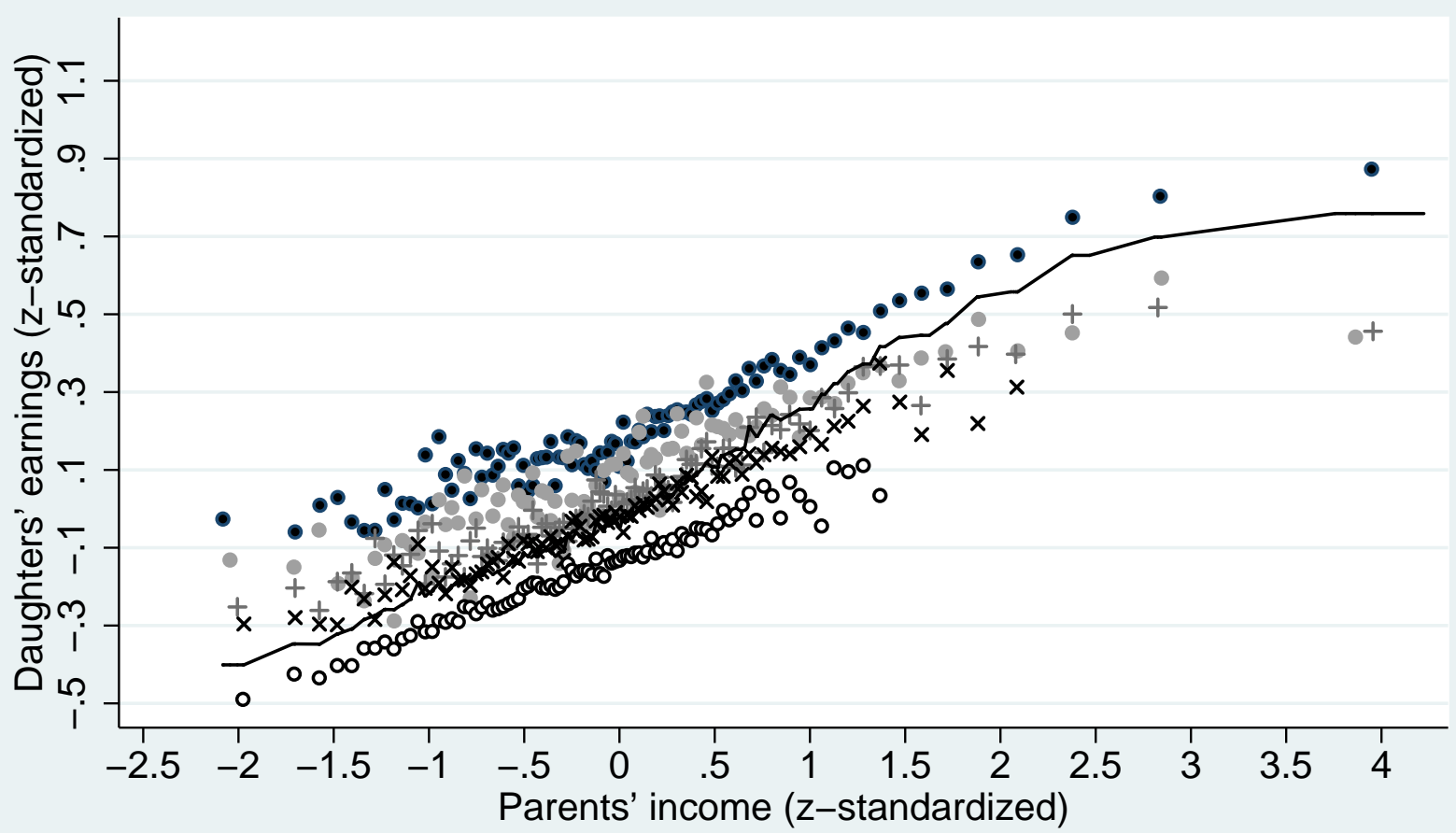

\begin{tabular}{|lll|}
\hline $\begin{array}{l}\text { - Both upper or middle } \\
+ \text { Mix upper/mid+manual }\end{array}$ & $\times$ & Both routine non-man. \\
- Both manual & $\times$ & Mix routine non-man.+man. \\
\cline { 2 - 2 }
\end{tabular}

Figure 5: Daughters' earnings by parental income and parental social class.

\section{Accounting for Other Characteristics of the Family of Origin}

The graphical exploration has provided us with the main story without any functional form restrictions, yet in order to be digestible the graphs had to suppress much detail. In order to address the full picture more systematically and to enable more detailed controls, I proceed with regression analyses, shown in Table 2 (men) and Table 3 (women). Guided by the patterns seen in the graphical analysis, income is introduced as a linear term and (in model 4) interacted with parental social class to verify that the within-class income-earnings slopes are similar across classes. Here, I use very extensive controls for parental education, with 47 dummies for both father and mother, and I also add controls for parental wealth, family type, sibship size/sibling order (22 dummies), parental immigrant background, birth cohort, and municipality of residence at age 15 . For ease of presentation, I suppress coefficients for control variables. The data cover entire cohorts and cannot be seen as a random sample of some super-population, so standard errors are uninformative 
and are therefore not shown (given the sample size, most coefficients are however statistically significant at $p<0.001$ ).

Comparing models 1 and 2 with model 3 , we confirm that parental social class and income contribute independently to children's earnings: only 28 percent of the earnings advantage of children from families with higher incomes is accounted for by parental social class, and 41-54 percent of the earnings differences between children from different parental social classes are accounted for by parental income. The partial associations (model 3) show the same pattern as Figures 4 and 5: children with parents in manual occupations earn on average 0.3-0.4 standard deviations less than those whose parents are in the upper or middle service class, and a standard deviation's difference in parental income corresponds to an average difference of around 0.2 standard deviations in child earnings. Overall, the associations (and the models' $R^{2}$ ) are slightly lower for daughters than for sons. ${ }^{5}$ In model 4 , we can also verify that, as suggested by Figures 4 and 5, the association between parental income and child earnings looks similar across classes. Note that in models $4-7$, the inclusion of interaction terms means that the interpretation of the income coefficient changes: It goes from representing the average income-earnings association to representing the income-earnings association in the social class reference category (both parents in upper middle or middle class).

In model 5, we see that parental wealth is modestly associated with children's earnings, and again, slightly more strongly so for men than for women. Wealth cannot, however, account for more than a marginal part of the differences in children's earnings across parental classes or parental income. Adding parental education to model 6, we see that, as expected, parental education can account for part of the earnings differences between children of parents in different social classes, and also a small part of the parental income-child earnings association, but substantial differences in child earnings across parental social classes and income remain. Model 7 in addition controls for birth cohort, family type, sibship size/birth order (interaction), parental immigrant status, cohort, and municipality of residence in childhood, and neither of these factors can account for the remaining social class differences to any substantial extent. However, the cohort and municipality dummies explain a small part of the intergenerational income-earnings association.

Figure 6 shows the results in model 7 in graphical form, illustrating how parental income (slope of the lines) and social class (distance between lines) are more strongly reflected in men's earnings than in women's. Recall that earnings are standardized within sex, so the estimates say nothing about sex differences in the level of earnings.

If parental social class is measured in a more detailed way, with 21 categories or even with 77 microclasses for both mother and father, the estimated income effect in model 3 decreases somewhat (men: from 0.227 to 0.214 [21 classes] or 0.216 [microclasses]; women: from 0.193 to 0.176 [21 classes] or 0.186 [microclasses]), but only minor differences remain after controlling for the other parental variables used in the final model. Thus, the independent effect of income in models 6 and 7 is only very slightly overestimated because of the coarse measurement of class. $R^{2}$ in the final model is identical when using the more detailed class measures. 


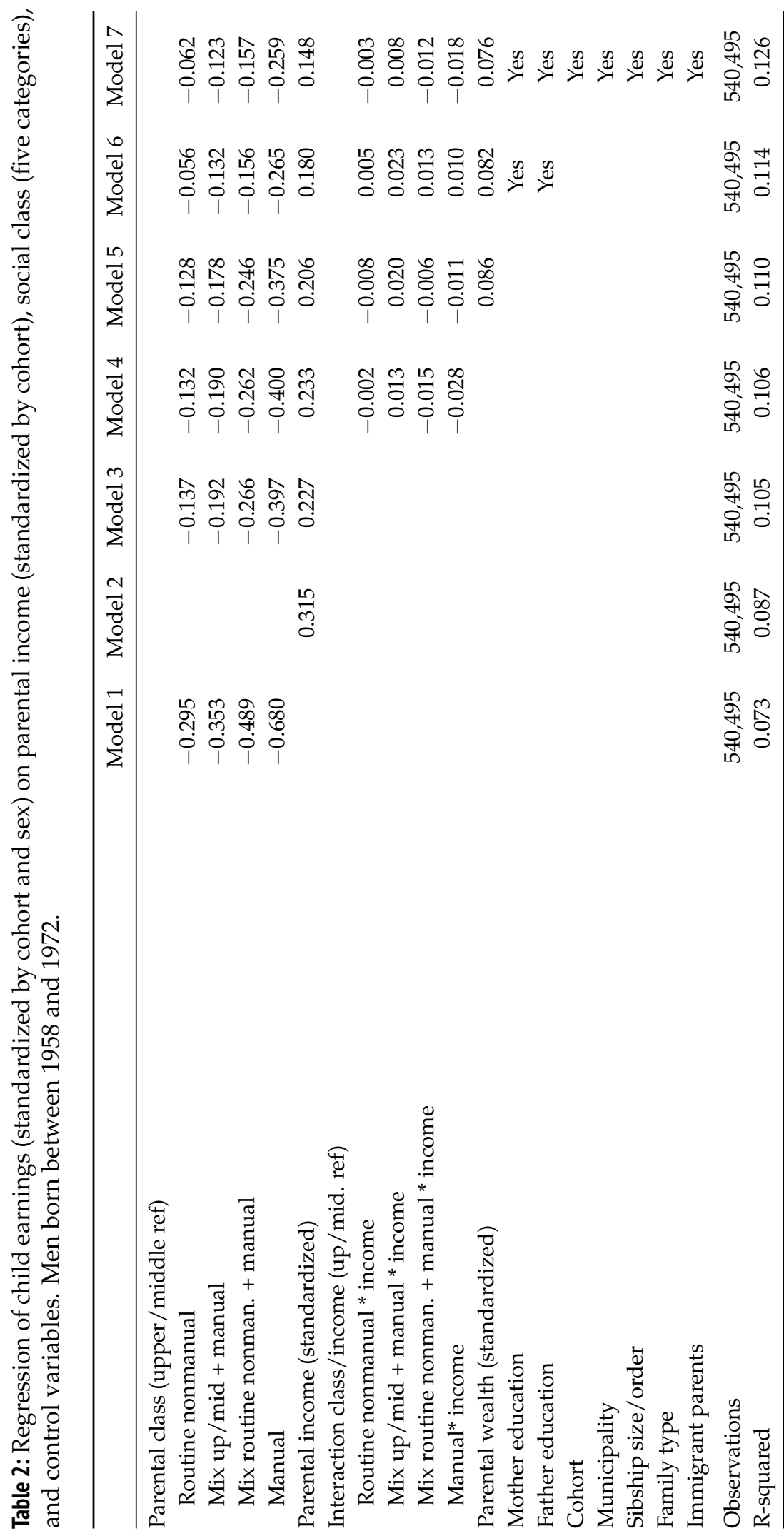




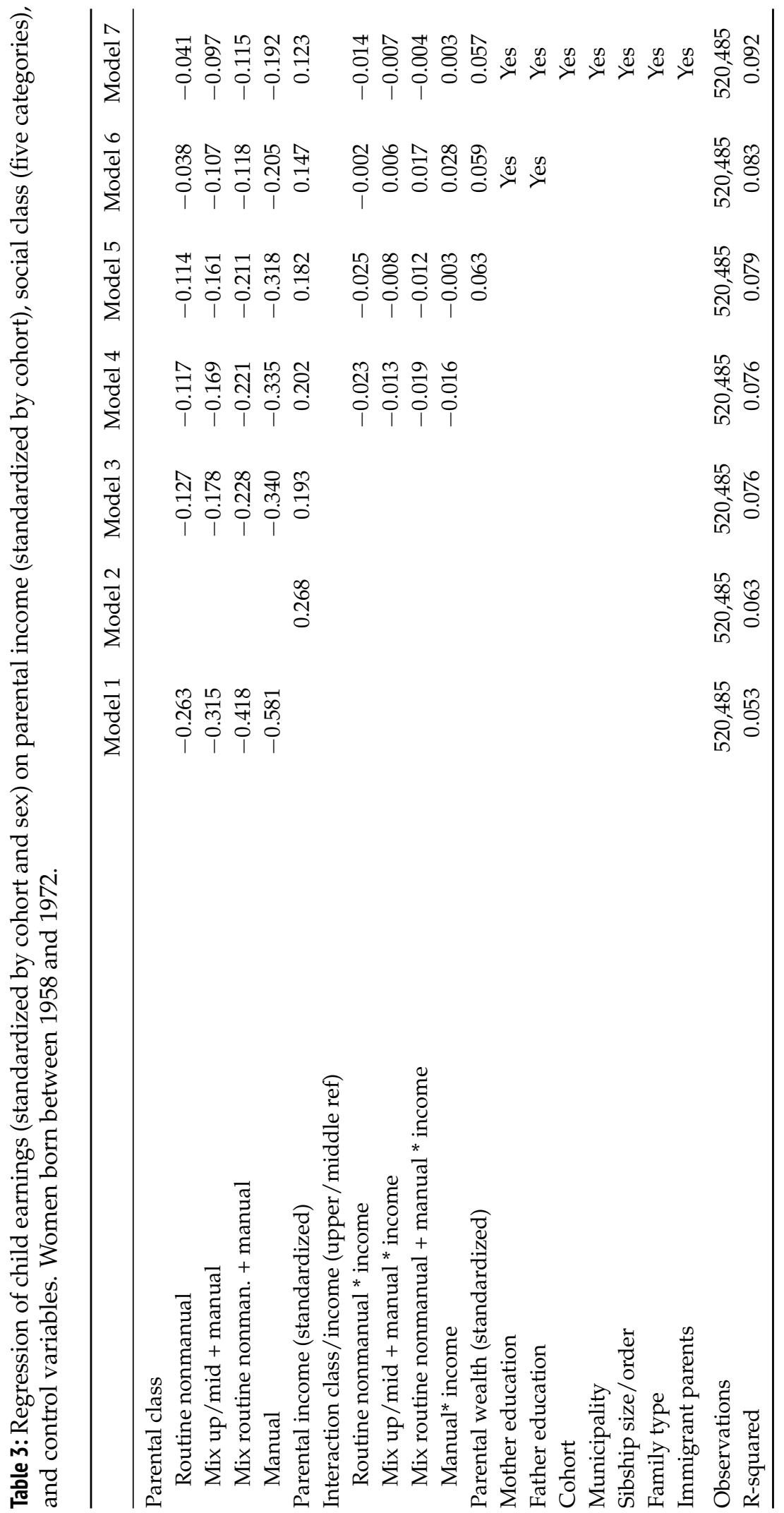



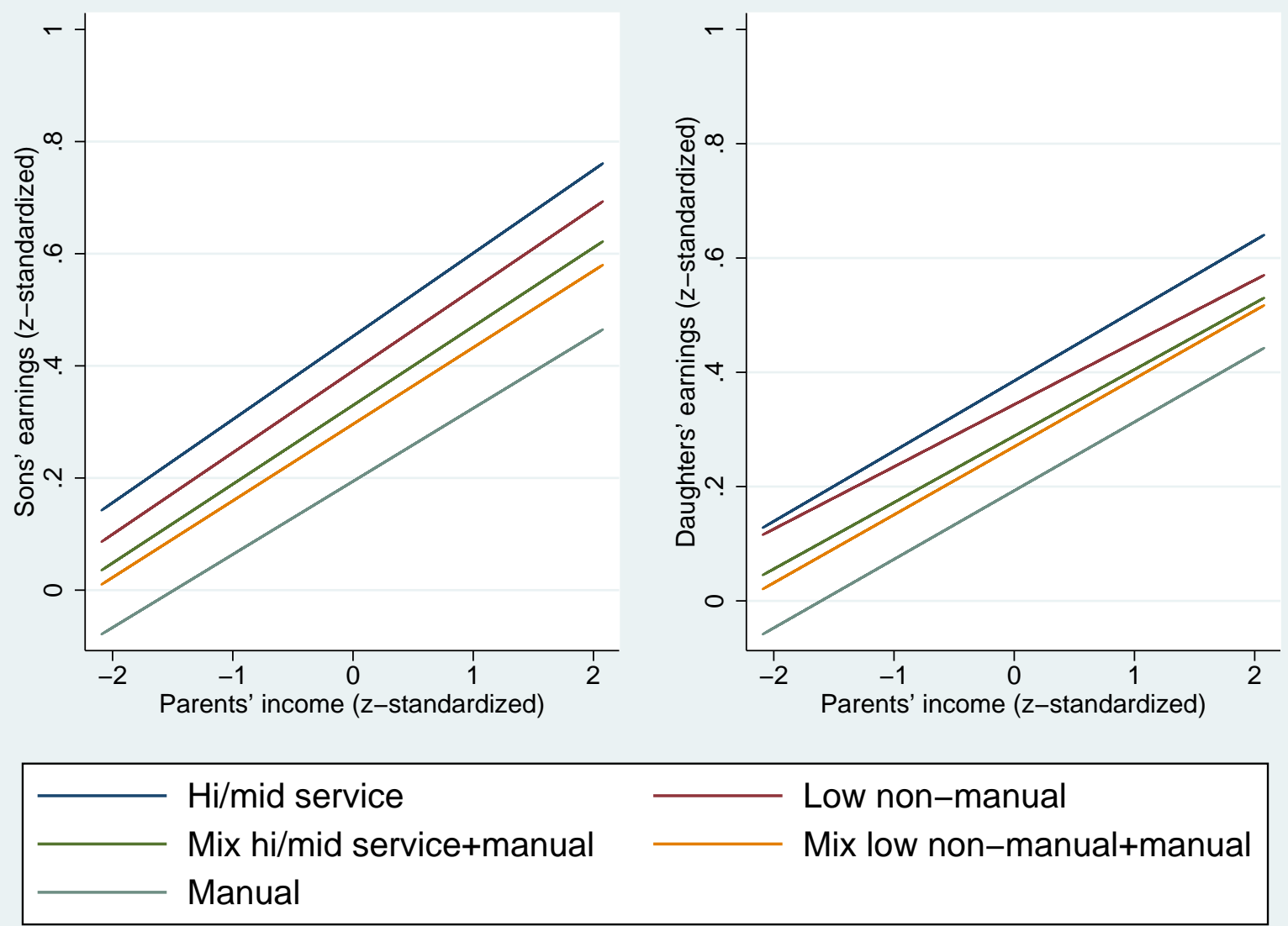

Figure 6: Predicted child earnings by parental income and class: men and women.

\section{How Large Is the Underestimation of Intergenerational Persistence if Using Only Parental Income or Parental Class?}

By now we know that parental income and social class have independent associations with child earnings, meaning that we will underestimate the transmission of advantage if using only one of these measures. I here look into the size of this underestimation by means of a decomposition of explained variance in children's earnings. The distinction between a decomposition of explained variance and one of the estimated effect terms (coefficients) is important. When independent variables are interrelated, as is the case here, a variable's "direct" contribution to the explained variance can be small, even when a variable has a large independent effect term. For example, parental income may have a large estimated effect on child earnings in a given parental class, but if most parents in a given class have similar incomes, the estimated income effect after controlling for class will not contribute much to explained variance in children's earnings. 
Table 4: Decomposition of explained variance (percent) in child earnings by parental social class (5 or 21 categories) and parental income.

\begin{tabular}{lcccccccc}
\hline & \multicolumn{3}{c}{ Explained variance in earnings } & \multicolumn{3}{c}{ Proportion of explained variance } \\
& \multicolumn{2}{c}{ Men } & \multicolumn{2}{c}{ Women } & \multicolumn{2}{c}{ Men } & \multicolumn{2}{c}{ Women } \\
Parental paths & EGP5 & EGP21 & EGP5 & EGP21 & EGP5 & EGP21 & EGP5 & EGP21 \\
\hline EGP-income & 5.5 & 6.1 & 3.9 & 4.5 & 0.52 & 0.57 & 0.52 & 0.58 \\
EGP, direct & 1.8 & 1.9 & 1.3 & 1.5 & 0.17 & 0.18 & 0.17 & 0.20 \\
Income, direct & 3.3 & 2.6 & 2.4 & 1.8 & 0.31 & 0.25 & 0.31 & 0.23 \\
\hline Variance explained by EGP and income & 10.5 & 10.7 & 7.6 & 7.8 & 1.00 & 1.00 & 1.00 & 1.00 \\
EGP-income & 5.5 & 6.1 & 3.9 & 4.5 & 0.75 & 0.76 & 0.75 & 0.75 \\
EGP, direct & 1.8 & 1.9 & 1.3 & 1.5 & 0.25 & 0.24 & 0.25 & 0.25 \\
\hline Variance explained, EGP only & 7.3 & 8.0 & 5.3 & 6.1 & 1.00 & 1.00 & 1.00 & 1.00 \\
EGP-income & 5.5 & 6.1 & 3.9 & 4.5 & 0.63 & 0.70 & 0.63 & 0.72 \\
Income, direct & 3.3 & 2.6 & 2.4 & 1.8 & 0.37 & 0.30 & 0.37 & 0.28 \\
\hline Variance explained, income only & 8.7 & 8.7 & 6.3 & 6.3 & 1.00 & 1.00 & 1.00 & 1.00 \\
\hline
\end{tabular}

Note: EGP5/EGP21 denote 5 and 21 categories of parental class; see Table 1 for classification.

Table 4 reports a two-variable decomposition based on successive comparisons of the marginal change in explained variance with different sets of independent variables, based on models $1-3^{6}$ in Tables 2 and 3 but also replacing the class variable in these models (five categories) with the more extensive one (21 categories). In an analysis with parental income only, or with only the detailed measure of parental social class, each can explain 8.7/8.0 percent (men) and 6.3/6.1 percent (women) of the variance in child earnings. Two-thirds of this represents the overlap between social class and income, so 6.1 (men) and 4.5 (women) percent of the total variation in child earnings is accounted for by parental class mediated through parental incomes. Out of the total variation in child earnings, 1.9 percent (men) and 1.5 percent (women) is accounted for by variations between parental social classes not due to differences in income, and another 2.6 percent (men) and 1.8 percent (women) by parental income differences unrelated to social class, so if combining parental social class and income in a model, the total explained variance is 10.7 percent (men) and 7.8 percent (women). As can be expected, the less-detailed measure of social class results in an overestimation of the unmediated contribution of income and an underestimation of the overlap. Using the more detailed measure of class, we also see that the direct contribution of parental income is relatively more important among men than among women.

Table 5 makes a similar decomposition, but also takes parental education into account, which makes for a more complex picture. In spite of adding a very comprehensive measure of parental education, the explained variance increases very little (seen also in Tables 2 and 3), meaning that the independent contribution of education to the explained variance in earnings is small ( 0.4 percent). The contribution of parental education to child earnings is thus almost entirely mediated by parental class and income. In total, 65-67 percent of the variance explained by parental characteristics is accounted for by parental education mediated through parental social class and/or income. If we observe only parental income or only 
Table 5: Decomposition of explained variance in child earnings by parental education, social class (EGP, 21 categories), and parental income.

\begin{tabular}{|c|c|c|c|c|}
\hline & \multicolumn{2}{|c|}{$\begin{array}{l}\text { Explained variance } \\
\text { in earnings }\end{array}$} & \multicolumn{2}{|c|}{$\begin{array}{c}\text { Proportion of } \\
\text { explained variance }\end{array}$} \\
\hline & Men & Women & Men & Women \\
\hline Education-EGP-income & 5.0 & 3.8 & 0.45 & 0.46 \\
\hline Education-EGP & 1.3 & 1.1 & 0.12 & 0.13 \\
\hline Education-income & 0.5 & 0.3 & 0.04 & 0.04 \\
\hline Education, direct & 0.4 & 0.4 & 0.04 & 0.04 \\
\hline EGP-income & 1.1 & 0.8 & 0.10 & 0.09 \\
\hline EGP, direct & 0.7 & 0.5 & 0.06 & 0.06 \\
\hline Income, direct & 2.2 & 1.4 & 0.20 & 0.18 \\
\hline Variance explained by education, EGP, and income & 11.1 & 8.2 & 1.00 & 1.00 \\
\hline Part captured by EGP, including education and income & 8.0 & 6.1 & 0.73 & 0.74 \\
\hline Part unrelated to EGP & 3.0 & 2.1 & 0.27 & 0.26 \\
\hline Variance explained by education, EGP, and income & 11.1 & 8.2 & 1.00 & 1.00 \\
\hline Part captured by income, including education and EGP & 8.7 & 6.3 & 0.79 & 0.77 \\
\hline Part unrelated to income & 2.3 & 1.9 & 0.21 & 0.23 \\
\hline Variance explained by education, EGP, and income & 11.1 & 8.2 & 1.00 & 1.00 \\
\hline
\end{tabular}

parental social class, each captures 73-79 percent of the total variation explained by the three sets of variables. If we observe parental income and social class but exclude education, however, we capture 96 percent of the total variance explained because education overlaps so strongly with income and social class.

\section{Relative Importance of Parental Income, Class, and Education for Child Earnings}

Tables 4 and 5 give a picture of how much of the variance in earnings that we capture with the use of single parental variables, but they do not straightforwardly say how much each of the three parental variables contributes to the explained variance because it is not obvious how the variance predicted by their overlaps should be allocated to the separate variables. Because parental education, social class, and income are strongly related, the part of the variance in each variable that is unrelated to the other independent variables is not very large (recall that these direct paths are not the same as the estimated direct effects). Using only the direct paths in Table 5, we can explain no more than 3.3 (men) and 2.3 (women) percent of the variance in child earnings, so overlaps are the essential part of the story.

Given that the temporal order is largely unambiguous-from education to occupation to incomes - one way of approaching the overlap is to allocate it all to education, concluding that parental education accounts for 65 (men) or 67 (women) percent of the total estimated intergenerational impact on child earnings, but almost exclusively through affecting social class and/or income. As argued by Blau and 
Duncan (1967), such a perspective makes sense when studying parents' careers, but not when the focus is on intergenerational transmission: from the child's viewpoint, parental education, occupation, and income are contemporaneous. To understand how intergenerational persistence happens, it would appear theoretically more appropriate to see the child as simultaneously exposed to all these parental factors (and other variables that they may proxy for). In line with this, an approach that decomposes the explained variance without assigning priority across variables is the so-called Shapley decomposition. The name refers to Shapley (1953), but the method has been independently suggested by various authors under different names (cf. Grömping 2007).

Just as the analyses in Tables 4 and 5, the method is based on comparisons of explained variances from successive models. In a multivariate model, the independent variables $X_{1}, \ldots, X_{k}$ can be entered in different order. Denote a particular independent variable by $X_{j}$, denote its position in an ordering by $r_{j}$, and denote a particular ordering of the independent variables by $r=\left(r_{1}, \ldots, r_{k}\right)$. Let $S_{1}$ be the subset of independent variables entered into the model before $X_{j}$ in order $r$, and let $S_{2}$ denote this subset plus $X_{j}$. (Furthermore, let $R_{S_{1}}^{2}$ and $R_{S_{2}}^{2}$ be the resulting $R^{2} \mathrm{~s}$ when running the model on these sets.) The part of explained variance $\left(R^{2}\right)$ assigned to $X_{j}$ given a particular order $r$ can then be written as

$$
R_{X_{j}}^{2} \mid r=R_{S_{2}}^{2}-R_{S_{1}}^{2}
$$

and the overall contribution of $X_{j}$ to $R^{2}$ is arrived at by taking the average of this marginal $R^{2}$ over all possible orderings $r$ :

$$
R_{X_{j}}^{2}=\frac{1}{k !} \sum_{r} R_{X_{j}}^{2} \mid r
$$

The results of these decompositions are given in Table 6, showing that parental education, social class, and income are of roughly equal importance in explaining child earnings - contributing about a third each to the total explained variancebut parental income being somewhat more important (40-44 percent of explained variance) than parental education and social class (27-32 percent of explained variance). The pattern of relative importance is similar for men and women, but each one of the three parental variables explains substantially more of the variance in sons' earnings than in daughters'.

\section{Conclusions}

In sociology and economics, we have voluminous separate literatures on social mobility and economic mobility, in which the standard practice is to treat a single parental characteristic (class or income) as an omnibus measure of parental advantage. This is a practice that makes it difficult to progress towards an understanding of which advantages matter for children and through which mechanisms transmission occurs. Disentangling the roles of different parental variables, as done 
Table 6: Shapley decomposition of the explained variance in child earnings.

\begin{tabular}{lccccccccc}
\hline & \multicolumn{3}{c}{ Explained variance in earnings } & \multicolumn{3}{c}{ Proportion of explained variance } \\
& Men & Men & Women & Women & Men & Men & Women & Women \\
Parental paths & EGP5 & EGP21 & EGP5 & EGP21 & EGP5 & EGP21 & EGP5 & EGP21 \\
\hline Parental education & 3.0 & 2.9 & 2.4 & 2.3 & 28 & 27 & 30 & 28 \\
Parental social class & 3.2 & 3.5 & 2.2 & 2.6 & 29 & 32 & 28 & 32 \\
Parental income & 4.8 & 4.6 & 3.4 & 3.2 & 44 & 42 & 42 & 40 \\
\hline Total & 11.0 & 11.1 & 8.1 & 8.2 & 100 & 100 & 100 & 100 \\
\hline
\end{tabular}

Note: EGP5/EGP21 denote 5 and 21 categories of parental class; see Table 1 for classification.

here, is a step towards such an understanding, and it also reduces the problem of underestimation of the transmission of advantage.

The most fundamental result of this article is that parents' social class and income have clearly independent associations with child earnings: Class matters at a given income and income matters within a given social class, and both associations are substantial in size. Thus, parental social class and income stand for different advantages that are linked to child earnings through different mechanisms, and we can say this with a high degree of confidence because measurement error in these data poses a much smaller problem than usual. Moreover, class is not merely picking up the effect of parental education, as the social class differences remain strong even at a given parental educational level. Although it is still not possible to say exactly which distinct advantages that social class and income represent, it is clear that sociologists are selling class short when defending it as a better measure of economic resources. It is clearly more.

As for the underestimation of the role of parental advantage, my results show that when we include only parental class or only parental income in the model predicting children's earnings, we underestimate the intergenerational transmission (as measured by explained variance in children's earnings) by around 25 percent, as compared to the case when both class and income are included in the model. Overall, parental income, occupation, and education carry roughly equal weight in explaining the variance in children's earnings, but all these parental variables explain much less of the variance in daughters' earnings (8 percent) than in sons' (11 percent). The estimated effects of social class and income do not proxy more than marginally for residential area during childhood, parental immigrant status, family type, or sibship size/sibling order, and despite using an extensive set of wellmeasured controls for these characteristics, they add only slightly to the explained variance in earnings once we know parental social class, income, and education. This suggests that sociodemographic characteristics of this kind do not capture any important advantages that income and social class bestow upon children (at least not when it comes to advantages that pay off in adult earnings), and neither do they pick up any crucial parental advantages not captured by income and social class. The fact that my uniquely extensive models of parental socioeconomic and demographic characteristics-even those including all controls and measuring social class by means of 77 microclasses for mothers as well as fathers-can account for no more than 13 (men) and 9 (women) percent of the variance in children's 
earnings must also be seen as good news: Swedish children's success is very far from determined by their parental socioeconomic circumstances.?

Another finding is that the social class of both parents matters, and although this is neither a new nor a surprising finding (see e.g., Beller 2009), it is important nevertheless as it builds an even stronger case against the still prevailing but obviously dated practice of studying only the social class of one parent (normally fathers' class or the dominant class). My demonstration of independent roles of income and class, and of mothers' and fathers' class, are also results relevant for the burgeoning field of multigenerational effects: if measuring parental background in terms of only class or only income, or in terms of only one parent's characteristics, large parts of the association between parental background and child outcomes will be unmeasured and left to be picked up by the measured variables for grandparents or other kin-hence overestimating their importance.

An interesting result is that the nonlinearity of the association between parental income and child earnings is in fact a compositional effect capturing the main effects of class: Within parental classes (defined as combinations of both parents' social class), the income-earnings association is close to linear. This calls into question the standard use of nonlinear transformations of income and earnings in the economic mobility literature, and it suggests that the considerable research efforts devoted to estimating and explaining nonlinearities in the intergenerational income association may be more fruitfully spent on broadening the analysis to include parental social class.

Because both parental income and class matter for children, and because they are only partly overlapping, it would make sense to start to seriously integrate the fields of social and economic mobility rather than stacking more studies onto the respective piles. In our integrative efforts, however, it is important to also consider child outcomes other than earnings, which was the outcome in focus here. Although earnings is a highly intuitive measure of advantage, which is surely related to a wide range of other advantages, it is important not to reduce the study of transmission of advantage to purely economic outcomes. These are issues that I develop in a companion paper. However, it is equally important to be explicit about advantages, so as not to lose the distinction between transmission of advantage (a vertical perspective) and transmission of differences (a horizontal perspective). Although both can indeed be important, interpretation of results are clearer if they are analytically separated.

\section{Notes}

1 I have estimated models involving children's educational and occupational paths, but in order to keep this article at a reasonable length, the child-side mechanisms are dissected thoroughly in a companion paper.

2 I have also constructed and used a measure of income stability, defined as the coefficient of variance (top-coded) of parental income over the same period as the mean income is taken. This measure varied only marginally across parental classes and had no substantive impact on the estimated class and income effects, so it is not included in the reported analyses. 
3 A categorization reflecting not only the combination of classes but also which class is the father's and which is the mother's would result in a large number of categories, and I refrain from doing this here as it would add too much complexity and require more space.

4 If zero earnings are excluded, the shape becomes more strongly nonlinear because of an almost flat slope at the very lowest end of the parental income distribution. Thus, part of the intergenerational persistence is driven by a higher proportion of children of low-income parents having more years with zero earnings.

5 When the earnings measure is defined to exclude earnings-related benefits, the parentchild associations are markedly underestimated for women.

6 Decompositions accounting for education are carried out below. Taking the other control variables into account makes the presentation more complex without affecting the substance of the results for our variables of interest (parental income, social class and education).

7 This conclusion may be qualified if extending the analysis to include multiple dimensions of advantage also on the child side (i.e., as dependent variables). See the final paragraph. It is of course also debatable whether $R^{2}$ is the appropriate measure here.

\section{References}

Beller, Emily. 2009. "Bringing intergenerational social mobility research into the twenty-first century: Why mothers matter." American Sociological Review 74:507528. https://doi.org/10.1177/000312240907400401.

Black, Sandra E. and Paul J Devereux. 2011. "Recent Developments in Intergenerational Mobility. Chapter 16, volume 4b." In Handbook of Labor Economics, pp. 1487-1541. Amsterdam: Elsevier.

Blanden, Jo. 2013. "Cross-Country Rankings in Intergenerational Mobility: A Comparison of Approaches from Economics and Sociology." Journal of Economic Surveys 27:38-73. https ://doi .org/10.1111/j.1467-6419.2011.00690.x.

Blanden, Jo, Paul Gregg, and Lindsey Macmillan. 2013. "Intergenerational persistence in income and social class: The impact of within-group inequality." Journal of the Royal Statistical Society, Series A 176:541-563. https://doi .org/10.1111/j . 1467-985X.2012.01053.x.

Blanden, Jo and Stephen Machin. 2007. Recent changes in intergenerational mobility in Britain. Report for the Sutton Trust.

Blau, Peter M. and Otis Dudley Duncan. 1967. The American Occupational Structure. New York: Wiley.

Bratsberg, Bernt, Knut Röed, Oddbjörn Raaum, Robin Naylor, Markus Jäntti, Tor Eriksson, and Eva Österbacka. 2007. "Nonlinearities in intergenerational earnings mobility: Consequences for cross-country comparisons." Economic Journal 117:c72c92. https://doi.org/10.1111/j.1468-0297.2007.02036.x. 
Breen, Richard and Jan O. Jonsson. 2005. "Inequality of Opportunity in Comparative Perspective: Recent Research on Educational Attainment and Social Mobility." Annual Review of Sociology 31:223-244. https ://doi . org/10 .1146/annurev . soc . 31.041304 .122232 .

Breen, Richard, Carina Mood, and Jan O Jonsson. 2016. “How Much Scope for a Mobility Paradox? The Relationship between Social and Income Mobility in Sweden." Sociological Science 3:39-60, DOI 10.15195/v3.a3. https://doi.org/10. 15195/v3.a3.

Clark, Gregory. 2014. The Son also Rises: Surnames and the History of Social Mobility. Princeton: Princeton University Press.

Clark, Gregory, Neil Cummins, Yu Hao, and Dan Diaz Vidal. 2015. "Surnames: A new source for the history of social mobility." Explorations in Economic History 55:3-24. https://doi.org/10.1016/j.eeh.2014.12.002.

Erikson, Robert and John H Goldthorpe. 1992. The Constant Flux: A Study of Class Mobility in Industrial Societies. Oxford: Clarendon Press.

Erikson, Robert and John H Goldthorpe. 2010. "Has social mobility in Britain decreased? Reconciling divergent findings on income and class mobility." British Journal of Sociology 61:211-230. https://doi .org/10.1111/j .1468-4446. 2010. 01310.x.

Gregg, Paul., Jan O. Jonsson, Lindsey Macmillan, and Carina Mood. 2013. “Understanding income mobility: the role of education for intergenerational income persistence in the US, UK and Sweden." Department of Quantitative Social Science Working Paper 13/12.

Grömping, Ulrike. 2007. "Estimators of Relative Importance in Linear Regression Based on Variance Decomposition." The American Statistician 61:139-147. https: //doi.org/10.1198/000313007X188252.

Hauser, Robert M. and John. R. Warren. 1998. "Socioeconomic indexes for occupations: A review, update, and critique." Sociological methodology 27:177-298. https://doi.org/10.1111/1467-9531.271028.

Heckman, James J, Hidehiko Ichimura, and Petra E. Todd. 1998. "Matching as an econometric evaluation estimator." Review of Economic Studies 65:261-294. https://doi.org/10.1111/1467-937X.00044.

Jonsson, Jan O. 2001. "Towards a Post-Fordist Life-Course Regime? Generational Changes in Transitions and Volatility. Chapter 1." In Cradle to Grave. Life-Course Change in Modern Sweden., edited by Jan O Jonsson and Colin Mills, pp. 1-28. Durham: Sociologypress. From 2009 on Routledge.

Jonsson, Jan O., David B. Grusky, Matthew Di Carlo, Reinhard Pollak, and Mary C. Brinton. 2009. "Micro-Class Mobility. Social Reproduction in Four Countries." American Journal of Sociology 114:977-1036. https ://doi .org/10.1086/596566. 
Jonsson, Jan O., Carina Mood, and Erik Bihagen. 2010. "Fattigdomens förändring, utbredning och dynamik [Poverty in Sweden: Trends, prevalence, and dynamics]." In Social Rapport 2010, pp. 90-126. Stockholm: Socialstyrelsen (National Board of Health and Social Affairs).

Mood, Carina, Jan O. Jonsson, and Erik Bihagen. 2012. "Socioeconomic Persistence across Generations: Cognitive and Noncognitive Processes. Chapter 3." In From Parents to Children. The Intergenerational Transmission of Advantage., edited by John Ermisch, Markus Jäntti, and Timothy Smeeding, pp. 53-83. New York: Russell Sage.

Pfeffer, Fabian. T. and Martin Hällsten. 2012. Mobility regimes and parental wealth: The United States, Germany, and Sweden in comparison. University of Michigan: PSC Report 12-766.

Shapley, Lloyd. 1953. A Value for n-Person Games. Cambridge: Cambridge University Press. https://doi.org/10.1515/9781400881970-018.

Solon, Gary. 2004. A model of intergenerational mobility variation over time and place. Cambridge: Cambridge University Press. https://doi.org/10.1017/ CB09780511492549.003.

Acknowledgements: I have benefited from helpful comments from members of the Levelof-Living team at the Swedish Institute for Social Research, and in particular from detailed comments given by Per Engzell, Robert Erikson, Michael Gähler, Jan O. Jonsson, and Georg Treuter.

Carina Mood: Swedish Institute for Social Research, Stockholm University. E-mail: carina.mood@sofi.su.se. 